\title{
Role of Feed Added Aniseed as Immunomodulant and Growth Promoter in Broiler Chicks
}

\author{
Riaz Ahmad ${ }^{1}$, Nila Chand ${ }^{1}$, FarmanUllah ${ }^{2,4 *}$, Muhammad Salim ${ }^{3}$, Seyed Mahdi Hosseini ${ }^{4}$, Momen \\ Khan $^{5}$, Inayat ur Rehman ${ }^{6}$, Sami Ullah Khan ${ }^{7}$, Asma Babar ${ }^{2}$ and Bhunesh ${ }^{2}$ \\ ${ }^{1}$ Department of Poultry Science, Khyber Pakhtunkhwa the Agricultural University Peshawar, Pakistan
}

${ }^{2}$ Faculty of Veterinary and Animal Sciences, Lasbela University of Agriculture, Water and 8 Marine Sciences, Uthal, Balochistan, Pakistan

${ }^{3}$ Department of Forestry and Wildlife Management, University of Haripur, Khyber Pakhtunkhwa, Pakistan

${ }^{4}$ Key Laboratory of Agricultural Animal Genetics, Breeding and Reproduction, Education Ministry of China, College of Animal Sciences and Technology, Huazhong Agricultural University, Wuhan 430070, Peoples Republic of China

${ }^{5}$ Livestock and Dairy Development, Khyber Pakhtunkhwa, Pakistan

${ }^{6}$ School of Marxism, China University of Geo Sciences (Wuhan), Hongshan District Region Wuhan, P.R.China

${ }^{7}$ Laboratory of Microbiology and Immunology, College of Veterinary Medicine, Institute of Preventive Veterinary Medicine, Sichuan Agricultural University, Chengdu, China

*Corresponding author: Dr. Farmanullah , Faculty of Veterinary and Animal Sciences, Lasbela University of Agriculture, Water and

Marine Sciences, Uthal, Balochistan, Pakistan,Email: farman_aup@yahoo.com; farman.vas@luawms.edu.pk

\section{ARTICLE INFO}

Received: 幽 August 26, 2020

Published: 㗀 September 08, 2020

Citation: Riaz Ahmad, Nila Chand, FarmanUllah, Muhammad Salim, Ali Raza Jahejo, et al. Role of Feed Added Aniseed as Immunomodulant and Growth Promoter in Broiler Chicks. Biomed J Sci \& Tech Res 30(1)-2020. BJSTR. MS.ID.004902.

Abbreviations: RCBD: Randomized Complete Block Design; FCR: Feed Conversion Ratio; HI: Hemagglutination Inhibition; IB: Bronchitis Disease; IBD: Infectious Bursal Disease; CHM: Chinese Herbal Medicine
ABSTRACT

A research study was conducted to investigate the effect of feed added aniseed on the immune response, lipid profile and overall performance of broiler chicks. Two hundred and forty, day old broiler chicks were randomly distributed into four groups designated as W, X, Y and Z and each group was further divided into two subgroups. Each subgroup was replicated three times with 10 checks per replicate for different treatments. One of the subgroups was vaccinated with ND, IB and IBD vaccine according to the normal schedule. Group W was kept as a control, while group X, Y and Z were treated with ground aniseed in feed @ 5, 10, and 15g/kg respectively.Body weight and feed conversion ratio were significantly $(\mathrm{P}<0.05)$ improved in group $\mathrm{X}$ as compared to other groups. No significant $(\mathrm{P}>0.05)$ difference was recorded in mean feed intake, dressing percentage, breast weight, leg, thigh, intestine, heart, liver, spleen and thymus, while significant $(\mathrm{P}>0.05)$ difference in bursa was recorded in group Y and gizzard in group Z. Group Z had significant $(\mathrm{P}>0.05)$ effect on the reduction of total cholesterol and triglycerides as compared to others. Nonsignificant $(P>0.05)$ difference in LDL values were found, however numerically high HDL values was found in group $\mathrm{W}$ as compared to other groups. Mean antibody titer against ND, IB and IBD was significantly $(\mathrm{P}<0.05)$ higher in group $\mathrm{Z}$. It is concluded that feeding of aniseed @ $(10 \mathrm{~g} / \mathrm{kg})$ added in feed is better for Improving body weight gain,FCR, immune response, increasing HDL level and decreasingLDL level.

Keywords: Higher Density Lipoprotein; Low Density Lipoprotein; New Castle Disease; InfectiousBronchitis; Infectious Bursal Disease

\section{Introduction}

Poultry feed a major factor, affecting the overall performance and cost of production of poultry birds, because feed segments in poultry production are $70-80 \%$ of the total cost. Balanced ration not only improve the production performance of broiler chicks, but 
also reduce per unit cost of production. Poultry nutritionists have been working, since the commercialization of poultry industry to enhance the efficiency of feed utilization by all possible economic measures. To improve the efficiency of feed, certain nonnutritive feed additives, like coccidiostats, antibiotics, enzymes and hormones are frequently used in poultry feed as growth promoter to ensure the pathogenic free environment in the intestine to facilitate the epithelium to absorb the nutrients more efficiently. The extensive use of these synthetic feed additives in poultry feed, resulted in the development of resistance in microorganisms to antibiotics and its residues are accumulated in meat and eggs, which is serious threat to human health. Concerted efforts are made to cope with this great challenge to investigate the efficiency of natural feed additives of significant importance both nutritionally and medically. The major sources of natural feed additives are medicinal plants. These medicinal plants grow abundantly in the northern hilly parts of Pakistan.

Medicinal plants contain numerous active chemical compounds, which perform vital functions both in human and animal body to eliminate toxic material from body and to act as antibacterial, antiviral, antifungal, antiparasitic with no side effects both in poultry and human beings but to improve the digestibility and overall performance of poultry birds. Aniseed (pimpinella anisum) is an annual herb, indigenous to Iran, India, Turkey and Pakistan. Anise oil has anothole (85\%) as active ingredient and also it contains eugenol, methylchavicol, anisaldehyde and estragole, as a medicinal plant, fundamental precondition for cost efficient poultry production. Aniseed has been used as immune stimulating and antiparasitic [1], antifungal; (Gangrade, 1991) and antipyretic and analgesic (Afif et al. 1994), anaphylaxis if an allergy exists), antibacterial (Gangrade et al. 1991), Antioxidant (Farag and Kawas 1998) and (Dixit, et al. 2005). It also gives relief to upper respiratory tract infection (Schicher, 2000). Moreover, the plant and specially its fruit essential oil has been used for treatment of some disease, including seizures and epilepsy [1]. Keeping in view the numerous medicinal properties of aniseed, worked out by many scientists, a research study was conducted on the use of aniseed in broiler production.

\section{Materials and Methods}

A research study was conducted to investigate the effect of different levels of feed added aniseed (Pimpinella anisum) on the overall performance, Lipid Profile and Immunity of broiler chicks at Khyber Pakhtunkhwa Agricultural University Peshawar, Poultry Farm.

\section{Experimental Design}

Randomized Complete Block Design (RCBD) was used in the present study. Two hundred and forty (240) day old broiler chicks were randomly divided in to four treatment groups, designated as $\mathrm{w}, \mathrm{x}, \mathrm{y}$ and $\mathrm{z}$. Each group was carrying two subgroups and each subgroup was replicated three times with ten (10) chicks in each replicate. One of the subgroups of the treated and control groups (W, X, Y and Z) were vaccinated against ND, IB and IBD. Chicks were kept in pens and were reared in an open sided house in pens. Feeder, drinker, bulb and other necessary materials were provided to chicks in each pen to maintain sound managemental and environmental conditions. Experiment was lasted for 35 days.

\section{Preparation of Aniseed}

The dry seed of Pimpinella anisum L. was purchased from local market and was ground with help of grinding machine. After grinding of Pimpinella anisum L. were added in commercial feed @ 5, 10 and $15 \mathrm{~g} / \mathrm{Kg}$ of feed and were fed to the treated groups. The ground seed was thoroughly mixed with feed for each group in to two steps. First a small portion of feed was mixed with the known amount of Pimpinella anisum L., and then this was added in the remaining feed to ensure proper uniform mixing.

\section{Data Recorded}

Data was recorded for water intake, feed intake and mortality on daily basis and body weight gain on weekly basis. Feed conversion ratio (FCR) was calculated on weekly basis by dividing weekly feed intake on weekly weight gain. Total FCR was calculated from these values. On the last day of study one bird from each replicate was live weighed and slaughtered. Head, feet, and all internal visceral organs including abdominal fat were removed and then the dress body will be weighed. The dress body weight was expressed in terms of dressing percentage. Dressed carcass of the birds was then cut in to different parts weight of thigh, leg and breast were recorded. Giblet (Heart, Liver and Gizzard) from slaughtered birds were collected and weights were recorded. Carcasses of each replicate were opened to weigh different lymphoid organs i.e. spleen, thymus and bursa, separately. Mean weight of lymphoid organs was calculated and relative weight of these organs to the body weight was calculated, using the following formula as described by Sharma et al. [2]. At the end of experiment, blood samples were collected for each replicate in test tubes. Test tubes were kept in slanting position at suitable temperature for serum separation; the separated serum was packed and labeled properly. It was subjected to heamagglutination inhibition (HI) test to determine its titer against Newcastle disease (ND) and infectious bronchitis disease (IB) and ELISA to measure its antibody level against infectious bursal disease (IBD) as described by Marquardt et al. [3].

\section{Data Analysis}

Averaged results were expressed as means and evaluated for statistical significance with an analysis of variance (Two factorial, Randomize Complete Block Design) test as described by Steel, et al. [4]. Statistical package (RCBD) was used for comparisons of 
all treatments with the control, and also for comparison between vaccinated versus non-vaccinated chicks, plus interaction of vaccinated and non-vaccinated chicks. The statistical package $\mathrm{M}$ STAT C was used to perform the analysis.

The statistical package M STAT C was used to perform the analysis.

Statistical Model: $Y i j=\mu+\alpha j+E i j$

Yij $=$ Yield subjected to $\mathrm{i}$ th chick and $\mathrm{j}$ th treatment.

$\mu=$ Population mean. $\alpha \mathrm{j}=$ treatment effect.

Eij $=$ Random error subjected to $i$ th chick and $j$ th treatment and

Table 1: Mean Feed intake, Body wt gain, FCR, Dress percentage, Breast, Thigh, Leg of broiler chicks fed different levels of feed added Aniseed.

\begin{tabular}{|c|c|c|c|c|c|c|c|}
\hline \multirow[t]{2}{*}{ Group } & Mean & Mean & Mean & Mean & Mean & Mean & Mean \\
\hline & Feed Intake (g) & Body wt Gain (g) & FCR & Dressing & Breast (g) & Thigh (g) & Leg (g) \\
\hline $\mathbf{w}$ & 1998.50 & $1011^{\mathrm{b}}$ & $1.87^{\mathrm{ab}}$ & 61.13 & 140.00 & 45.83 & 45.67 \\
\hline $\mathbf{X}$ & 2026.67 & $1235^{\mathrm{a}}$ & $1.75^{\mathrm{b}}$ & 62.30 & 138.00 & 46.17 & 45.50 \\
\hline $\mathbf{Y}$ & 2110.00 & $1087^{\mathrm{ab}}$ & $1.90^{\mathrm{ab}}$ & 60.45 & 146.50 & 47.17 & 45.50 \\
\hline $\mathbf{Z}$ & 2110.33 & $1059^{a b}$ & $1.98^{\mathrm{a}}$ & 62.42 & 150.67 & 49.83 & 49.67 \\
\hline \multicolumn{8}{|c|}{ Vaccination } \\
\hline Vac & 2048.333 & 1069.75 & 1.88 & 62.333 & 142.17 & 47.833 & 47.833 \\
\hline Non-vac & 2069.917 & 1072.00 & 1.86 & 60.817 & 145.42 & 46.167 & 45.333 \\
\hline \multicolumn{8}{|c|}{ Interaction } \\
\hline W x Vac & 2077.000 & 1028.00 & 1.96 & 61.667 & 142.67 & 46.333 & 47.000 \\
\hline W x Non-Vac & 1920.000 & 1046.33 & 1.76 & 60.600 & 137.33 & 45.333 & 44.333 \\
\hline Xx Vac & 2022.333 & 1152.00 & 1.70 & 63.900 & 131.00 & 47.333 & 47.667 \\
\hline X x Non-Vac & 2031.000 & 1092.33 & 1.80 & 60.700 & 145.00 & 45.000 & 43.333 \\
\hline Y x Vac & 2056.333 & 1078.33 & 1.90 & 60.500 & 147.00 & 49.333 & 48.333 \\
\hline Y x Non-Vac & 2145.667 & 1090.00 & 1.90 & 60.400 & 146.00 & 43.000 & 42.667 \\
\hline $\mathrm{Z} \times$ Vac & 2037.667 & 1020.66 & 1.96 & 63.267 & 148.00 & 48.333 & 48.333 \\
\hline Z x Non-Vac & 2183.000 & 1059.33 & 2.00 & 61.567 & 153.33 & 51.333 & 51.000 \\
\hline
\end{tabular}

Note: abc: Means within the same row having different superscripts are significantly different $(\mathrm{P}<0.05)$.

Significant difference was found in different treatments; Mean body weight gain was found higher $(\mathrm{P}<0.05)$ in group $\mathrm{X}$, receiving aniseed infusion @ 5 grams of aniseed per kg of feed as compared with other groups. No significant effect was found between vaccinated and non-vaccinated groups. The higher body weight gain of group X, receiving minimum amount of ground aniseed could be correlated with the work done by Mavromichalis et al. (2003), who reported that (pimpinella anisum) is responsible for $5 \%$ live weight gain in pig and also in line with Hernandez, et al. [5], who observed
Eij is normally distributed with zero (0) mean and constant variance $\delta 2$ i.e. $E i j \sim N(O . \delta 2)$.

\section{Results and Discussion}

Performance of broiler during the experimental period

\section{Body Weight Gain}

Chicks were weighed on day first and then at the end of each week, to determine weekly body weight gain by subtracting the initial weight from final weight, recorded at the end of each, week Cumulative weight gain was Mean body weight gains per chick were 1011, 1235, 1087 and 1059 grams respectively and is given in (Table 1). 
group. Finding of the present research study can be compared with the findings of the Fairley, et al. [8].

\section{Feed Consumption}

Mean feed intake per chick of different treatments and control group W, X, Y and Z are 1998.50, 2026.67, 2110.00, 2110.33 is given in (Table 1). Mean feed intake was not affected by different treatment of Aniseed. The findings of present research study could be coincided with the findings of Stanly et al. (2004), which conducted experiments on feeding antibiotics in broiler chicks and concluded that antibiotics as growth promoter resulted in either insignificant difference or depressed feed intake among treated groups. Our results are coincided with the finding of the Guo, et al. [9], who reported that feed intake of the extract supplemented groups were not significantly different from those of the antibiotic groups. Kubo et al., 1992 and therefore could be effectively utilized as potential alternative as growth promoter. Finding of present research study could be coincided with the finding of proud foot et al. (1990) who conducted experiments, feeding antibiotics to broiler chicks and noticed that antibiotics resulted in insignificant difference among treated and control groups.

\section{Feed Conversion Ratio}

Mean FCR value per chick of different groups are 1.87, $1.75,1.90$ and 1.98 respectively and is indicated in (Table 1). Significant differences were recorded among the groups. Group $\mathrm{X}$ had significantly $(\mathrm{P}<0.05)$ the lowest FCR than other groups. No significant difference was found between groups $\mathrm{W}$ and $\mathrm{Y}$ vaccinated and non-vaccinated. The results are in agreement with the findings of Deek, et al. [7], who concluded that addition of pimpinella anisum to feed improve FCR upto $10.9 \%$. In a series of research work conducted on medicinal herbs at this university Sajjad, et al. [10] reported better FCR in broiler chicks, fed with habek mint and aniseed that support the findings of this research study. The result of the present study can be supported by Elwinger et al. (1993), who reported that Z. officinal has growth promoting effect and better-feed conversion efficiency in broiler chicken production. Results of present study are also in agreement with the result of Jamrose and Kamel (2002), who observed improvement of $8.1 \%$ and daily weight gain and $7.7 \%$ in FCR in seventeen day old pullets fed a diet supplemented with a herbal plants extract. Kakar, et al. [11] have come up with considerable better FCR infavour of our investigations using Berberis lycium herbal, ginger and aniseed extract in drinking water of broiler chicks respectively.

\section{Dressing Percentage}

Mean dressing percentage of different groups are 61.13, 62.23, 60.45 and 62.42 and for vaccinated and non vaccinated 62.333 and 60.817 is shown in (Table 1$)$. Non-significant $(\mathrm{P}>0.05)$ differences were reported among all the groups. The result of our study are an contrast with Bhatti et al. (1996) and Izat, et al. [12], who fed antibiotic to broiler chicks and reported significantly higher
$(\mathrm{P}<0.05)$ dressing percentage in broiler chicks. Guo, et al. [9], who reported that the birds fed Chinese herbal medicine (CHM group), had better growth and dressing performance. Our results are in line with the results of Deek, et al. [7], who reported that aniseed had no significant effect on dressing percentage. The findings of the present study are in contrast with the result of Ismail et al. [13], who reported higher $(\mathrm{P}<0.05)$ dressing percentage, using medicinal herbs curcuma longa in broiler chicks. Non-significant findings are reported by Chand, et al. [14], Kakar, et al. [11].

\section{Breast Weight}

Mean weight of breast for group W, X, Y and Z was 140.00, $138.00,146.00$ and $150.67 \mathrm{gm}$ respectively. It was observed that grounded aniseed had no influence $(\mathrm{P}>0.05)$ effect on the mean weight of breast among the treatments and non-significant between the vaccinated and non-vaccinated. Our observation could be supported with the finding of Deek, et al. [7], who noticed that aniseed, fed to broiler chicks, resulted in no significant differences in mean breast weight then control group. Result of the present study are in agreement with the findings of Ismail et al. [13], who reported no significant effect on the mean weight of breast using medicinal herbs curcuma longa in broiler chicks. The results of the present study are in agreement with the result of Chand, et al. [14], who feed herbal plants to brioler chicks and found that herbal extracts of the plants have no significant effect on the breast weight of broiler chicks. The results could be correlated with Sajjad, et al. [10], who reported that medicinal herb extracts ( $P$. Anisum ) given in drinking water had no significant effect $(\mathrm{P}>0.05)$ on the mean breast of broiler chicks.

\section{Thigh Weight}

Mean weight of thigh for groups W, X, Y and Z was 45.83, $46.17,47.17$ and 49.83 gm respectively. Four experimental groups are given in (Table 1). No significant $(\mathrm{P}>0.05)$ difference was recorded on the weight of thigh among the treatments and nonsignificant between the vaccinated and non-vaccinated and also non-significant among the interaction. Our observation could be supported with the finding of Deek, et al. [7], who noticed that aniseed, fed to broiler chicks, resulted of the present study are in agreement with the result of Ismail et al. [13], who reported no significant effect on the mean weight of thigh using medicinal herbs urcuma longa in broiler chicks. The results of the present study are in agreement with the result of Chand, et al. [14], Who feed herbal plant to broiler chicks and found the herbal extract of the plant have no significant effect on the thigh weight of broiler chicks. The result of the present research are correlated with the result of the Kakar, et al. [11] who fed different levels of ginger extract and found no significant effect on the mean weight of thigh. The result could be correlated with Sajjad, et al. [10] who reported that medicinal herb extract, (P. Anisum) given in drinking water had no significant effect $(\mathrm{P}>0.05)$ on the mean thigh weight of broiler chicks. 


\section{Leg Weight}

Mean weight of led for groups W, X, Y and Z was 45.67, $45.50,45.50$ and 49.67 gm respectively. No significance $(P>0.05)$ difference was recorded among the treatments and non-significant between the vaccinated and non-vaccinated. It was observed that ground Aniseed mixture had no significance $(\mathrm{P}>0.05)$ effect on the mean weight of leg, however findings of the present research study are in contrast with the findings of Izat, et al. [12], who observed that antibiotics fed to broilers chicks, had significant effect upon leg weight. Our observation could be supported with the findings of Deek, et al. [7], who notice that Aniseed , feed to broiler chicks, result in no significant difference in mean leg weight than control group. The result of the present research are correlated with the result of Kakar, et al. [11] who fed different levels of ginger extract and found no significant effect on the mean weight of leg. The result could be also correlated with Sajjad, et al. [10] who reported that medicinal her extract, ( $p$. Anisum) given in drinking water had no significant effect $(\mathrm{P}>0.05)$ on the mean leg of broiler chicks. Result of the present study are in agreement with the result of Ismail et al. [13], who reported that no significant effect on the mean weight of leg using medicinal herbs curcuma longa in broiler chicks.

\section{Heart and Gizzard}

There was no significant difference $(\mathrm{P}>0.05)$ was observed in mean weight of heart i.e. (7.17, 7.33, 7.00 and 8.33) in the present study shown in (Table 2). However, significant difference $(\mathrm{p}<0.05)$ was observed in the gizzard i.e. $(24.17,35.50,26.00$ and 28.33). It means that grounded aniseed, having antimicrobial and antibiotics like properties, have no influence on either increasing or decreasing the relative weights of heart and these finding are therefore in contrast to the results of the Fairley et al. [8]. He reported that a significant increase occurred in the proportions of giblets, when broiler chicks were fed an antibiotic avoparcin.

Table 2: The mean Liver, Gizzard, Heart, Bursa, Spleen, Thymus of broiler chicks fed different levels of feed added Aniseed.

\begin{tabular}{|c|c|c|c|c|c|c|}
\hline \multirow{2}{*}{ Group } & Mean & Mean & Mean & Mean & Mean & Mean \\
\hline & Liver (g) & Gizzard (g) & Heart (g) & Bursa (g) & Spleen (g) & Thymus (g) \\
\hline $\mathbf{w}$ & 33.333 & $24.17^{\mathrm{b}}$ & 7.17 & 1.83 & 1.45 & 2.43 \\
\hline $\mathbf{x}$ & 33.333 & $35.50^{\mathrm{a}}$ & 7.33 & 2.16 & 1.51 & 2.13 \\
\hline $\mathbf{Y}$ & 32.500 & $26.00^{\mathrm{ab}}$ & 7.00 & 2.26 & 1.70 & 2.75 \\
\hline $\mathbf{Z}$ & 36.333 & $28.33^{\mathrm{ab}}$ & 8.33 & 2.11 & 1.73 & 2.35 \\
\hline \multicolumn{7}{|c|}{ Vaccination } \\
\hline Vac & 33.500 & $25.000^{\mathrm{a}}$ & 7.417 & 2.35 & 1.62 & 2.43 \\
\hline Non-vac & 34.250 & $32.000^{\mathrm{b}}$ & 7.500 & 1.83 & 1.57 & 2.40 \\
\hline \multicolumn{7}{|c|}{ Interaction } \\
\hline W x Vac & 33.333 & 23.333 & 7.333 & 1.90 & 1.43 & 2.93 \\
\hline W x Non-Vac & 33.333 & 25.000 & 7.000 & 1.767 & 1.46 & 1.93 \\
\hline $\mathrm{X} \times \mathrm{Vac}$ & 32.000 & 22.000 & 7.333 & 2.700 & 1.20 & 1.60 \\
\hline $\mathrm{X} x$ Non-Vac & 34.667 & 29.000 & 7.333 & 1.633 & 1.83 & 2.66 \\
\hline Y X Vac & 35.333 & 27.667 & 7.000 & 2.567 & 2.13 & 2.76 \\
\hline Y x Non-Vac & 29.667 & 24.333 & 7.000 & 1.967 & 1.26 & 2.73 \\
\hline $\mathrm{Z} \times$ Vac & 33.333 & 27.000 & 8.000 & 2.267 & 1.73 & 2.43 \\
\hline Z x Non-Vac & 39.333 & 29.667 & 8.667 & 1.967 & 1.73 & 1.96 \\
\hline
\end{tabular}

Note: Means within the same row having different superscripts are significantly different $(\mathrm{P}<0.05)$.

\section{Liver Weight}

The result of liver weight shown in (Table 2) i.e. $(33.333,33.333$, 32.500 and 36.333 ) in this study was not effected significantly in either treated or control groups and are coincided with the findings of Wang and Hacker (1993), who reported that Chinese herbal medicine antibiotic influenced significantly the Giblet weight in broiler chicks. Our results are also parallel to with the finding of Stanley et al. (2004), who evaluated that the effect of lusalocid, an anticoccidial feed additive significantly affected the liver weight. Result of the present study are in agreement with the result of Ismail et al. [13], who reported non significant effect on the mean weight of liver, using medicinal herbs curcuma longa in broiler 
chicks. The present findings justify the findings of Hernandez, et al. [5,9], which fed herbal drugs to broiler chicks and reported non significant effect on the mean weight of liver of broiler chicks.

\section{Bursa}

Mean weight of bursa for group W, X, Y and Z was 1.90, 1.93, $2.08,1.80$ and that of vaccinated and non-vaccinated was 1.46 and $1.89 \mathrm{gm}$ respectively. It was observed that the ground aniseed $(P$. anisum) had significant ( $\mathrm{P}>0.05$ ) effect on the mean weight of bursa among the treated and between the vaccinated and non-vaccinated groups. Mean weight bursa was significantly $(\mathrm{P}<0.05)$ higher in group $\mathrm{Y}$ and vaccinated group. However, group interaction was not effected significantly. The results could be correlated with Kakar, et al. [11] who reported that medicinal plants had no significant effect on the mean weight of Bursa of broiler chicks. Similar findings are also reported by Sajjad, et al. [10] and Niazi, et al. [15] who fed different levels of (P. anisum) and B. lyceum extract respectively and found no significant difference in mean weight of Bursa.

\section{Spleen}

Mean weight of spleen for group W, X, Y and Z was 1.182, 1.55, 2.08 and 1.37 and subgroups of vaccinated and non-vaccinated were 1.96 and $1.89 \mathrm{gm}$, respectively. No significant $(\mathrm{P}>0.05)$ difference was recorded among the treated and between the vaccinated and non-vaccinated groups. However mean spleen weight was numerically higher in-group $\mathrm{Z}$ than other groups. Findings of the present study can be compared with the findings of Kakar, et al [11] who reported that ginger extract, given in drinking water had no significant effect on the mean weight of spleen of broiler chicks. Similar findings are also reported by Sajjad, et al. [10] and Niazi, et al. [15] who fed different levels of (P. anisum) and B. lyceum extract respectively and found no significant difference in mean weight of spleen.

\section{Thymus}

Mean weight of thymus for group W, X, Y and Z was 2.18, 2.20, 1.50 and 1.94 and subgroups of vaccinated and non-vaccinated were 2.29 and 1.68gm respectively. No significance $(P>0.05)$ difference was recorded in the mean weight of thigh among the treated and between the vaccinated and non-vaccinated groups. However mean weight of thymus was numerically higher in-group $\mathrm{Z}$ than other groups. The results could be correlated with Kakar, et al. [11] who reported that herbal medicines had no significant effect on the mean weight of thymus of broiler chicks. Similar findings are also reported by Sajjad, et al. [10] and Niazi, et al. [15] who fed different levels of (P. anisum) and B. lyceum extract respectively and found no significant difference in mean weight of thymus.

\section{HI Antibody Titer Against ND}

Significantly differences were observed among all the groups against ND. Highest $(\mathrm{P}<0.05)$ antibody was recovered in group $\mathrm{Z}$, while non significant values were found between vaccinated and group in interaction which shown in (Table 3). The values of all the groups are below the normal protected level. The result of present research are strongly opposed by the result of Sajjad, et al. [10] who fed different levels of ( $P$. anisum) extract and found no significant difference among the treated and control group against ND in broiler chicks. The finding of present study can be compared with the similar finding of Kakar, et al. [11], who fed ginger extract and observed higher antibody titer against ND than control group

\section{HI Antibody Titer Against IB}

Mean antibody titer against IB for groups W, X, Y and Z was $1.33,2.33,3.67$ and 4.83 respectively. It was observed that mean antibody titer against IB was significantly $(\mathrm{P}<0.05)$ higher in-group $\mathrm{Z}$ and among the group interaction, will non significant between vaccinated and non vaccinated groups. The IB value of group $\mathrm{W}$ is within the normal range of protected level (500). The results of present research are disagreed with the findings of Sajjad, et al. [10] that fed different levels of (P. Anisum) extract and found no significant difference among the treated and control groups against IB.

\section{ELISA Antibody Titer Against IBD}

Mean antibody titer against IBD for groups $\mathrm{W}, \mathrm{X}, \mathrm{Y}$ and $\mathrm{Z}$ was 896.33, 1170.00, 1332.00, and 2229.17 respectively. Mean antibody titer against IBD was significantly $(\mathrm{P}<0.05)$ higher ingroup $\mathrm{Z}$ among the treated and in vaccinated group interaction. The antibody titre of IBD in group $\mathrm{Z}$ has the highest level against the normal (1000) protected level. Our observation can be compared with the observation of Wheeler, et al. [6], who noticed that herbal drugs had anti stress and immunomodulatry property in chicken. The result can also be justified by the findings of Kakar, et al. [1012] who reported that medicinal herb extract, given in drinking water had significant effect $(\mathrm{P}<0.05)$ on the mean antibody titer against IBD of broiler chicks.

\section{Economics of Research Trial}

One objective of the present study was to determine the feasibility of addition of aniseed in commercial broiler production under local condition. Economics were calculated on terms of feed cost including the cost of aniseed gross return. Mean feed cost per chick was RS 33.2, 33.2, 33.8 and 33.8 groups W, X, Y and Z. subgroups of vaccinated and non-vaccinated was 32.8 and 33.7 respectively as presented in (Table 3 ). Mean gross return per chick was $72.7,72.6,85.8$ and 72.9 for group $\mathrm{W}, \mathrm{X}, \mathrm{Y}$ and $\mathrm{Z}$ and subgroups of vaccinated and non-vaccinated was 74.9 and 72.1 respectively as presented in (Table 3 ). Mean feed cost per chick was not significantly $(\mathrm{P}>0.05)$ affected among the treatments and between the vaccinated and non-vaccinated, however gross return was found significantly $(\mathrm{P}<0.05)$ higher in group $\mathrm{Y}$ and nonsignificant between the vaccinated and non-vaccinated subgroups. Results of the present study are in agreement with the result of Ismail et al. [13], who reported that significant effect was found 
in the economics of chicken using medicinal herbs curcuma longa in broiler chicks. The observation of our research study are also supported by the finding of Kakar, et al. [11] who calculated that
(P. Anisum) and (Z. Officinal )given in drinking water respectively had significant effect $(\mathrm{P}<0.05)$ on the gross return of broiler chicks [16-20].

Table 3: Mean ND, IB and IBD of broiler chicks fed different levels of Aniseed.

\begin{tabular}{|c|c|c|c|}
\hline \multirow{2}{*}{ Group } & Mean & Mean & Mean \\
\hline & ND & IB & IBD \\
\hline $\mathbf{W}$ & $0.167^{c}$ & $2.16^{b}$ & $896.33^{b}$ \\
\hline $\mathbf{X}$ & $1.333^{\mathrm{bc}}$ & $2.33^{\mathrm{b}}$ & $1170.00^{\mathrm{ab}}$ \\
\hline $\mathbf{Y}$ & $2.167^{\mathrm{ab}}$ & $3.67^{\mathrm{ab}}$ & $1332.00^{\mathrm{ab}}$ \\
\hline $\mathbf{Z}$ & $3.667^{\mathrm{a}}$ & $4.83^{\mathrm{a}}$ & $2229.17^{\mathrm{a}}$ \\
\hline \multicolumn{4}{|c|}{ Vaccination } \\
\hline Vac & 1.500 & 2.667 & $1434.667^{\mathrm{a}}$ \\
\hline Non-vac & 2.167 & 3.833 & $1379.083 b$ \\
\hline \multicolumn{4}{|c|}{ Interaction } \\
\hline W x Vac & 0.000 & 2.000 & 924.667 \\
\hline W x Non-Vac & 0.333 & 2.333 & 850.000 \\
\hline $\mathrm{X} \times$ Vac & 1.000 & $1.667^{\mathrm{a}}$ & 1323.333 \\
\hline X xNon-Vac & 1.667 & $3.000^{\mathrm{b}}$ & 1016.667 \\
\hline Y x Vac & 1.667 & $2.667^{\mathrm{a}}$ & 1435.333 \\
\hline Y xNon-Vac & 2.667 & $4.667^{b}$ & 1228.667 \\
\hline Z x Vac & 3.333 & 4.333 & 2037.333 \\
\hline Z xNon-Vac & 4.000 & 5.333 & 2421.000 \\
\hline
\end{tabular}

Note: Means within the same row having different superscripts are significantly different $(\mathrm{P}<0.05)$.

\section{Conclusion}

It is concluded from the finding of the present research study that grinded aniseed (Pimpinella anisum) @ 5g/kg of feed had higher body weight gain, dressing percentage (62.42\%) and better FCR (1.75). Mean antibody titer against ND, IB and IBD was higher by feeding grinded aniseed (Pimpinella anisum) @ 10g/kg of feed. Mean percent mortality was higher by feeding grinded aniseed (Pimpinella anisum) @ 10g/kg of feed. Mean feed cost was non significant and gross return was higher by feeding grinded aniseed.

\section{Recommendations}

Based on the result of present research study it is indicated that aniseed (Pimpinella anisum) could be effectively utilized in broiler chicks to improve the growth performance, immunity gross return and to lower serum lipid. Further studies are needed to find out the effect aniseed (Pimpinella anisum) in layer and breeder production.

\section{References}

1. Mehmet C, Talat G, Dalkilic B, Ertas ON (2005) The Effect of Anise Oil (Pimpinella anisum L.) On Broiler Performance. International Journal of Poultry Science 4(11): 851-855.

2. Sharma LK, Madina BR, Chaturvedi P, Sangwan RS, Tuli R (2007) Molecular cloning and characterization of one member of 3beta-hydroxy sterol glucosyltransferase gene family in Withania somnifera. Arch Biochem Biophys 460(1): 48-55.

3. Marquardt WW, Johnson RB, Odenwald WF, Schlotthoken BA (1980) An indirect enzyme linked immunosorbant assay (ELISA) for measuring antibodies in chickens infected with IBD. Avian Dis 24(2): 375-385.

4. Steel RGD, Torrie JH (1981) principles and procedures of statistics: A biometrical approach. $2^{\text {nd }}$ (Edi.). McGraw-Hill, Singapore.

5. Hernandez F, Madrid J, Garcia V, Orengo J, Megias MD (2004) Influence of two plant extract on broiler performance, digestibility, and digestive organ size. Poult Sci 83(2): 169-174.

6. Wheeler GE (1994) Use of a herbal supplement to reduce the effects fo stress in intensively reared chickens. Ind J Indig Med 11(1): 51-60.

7. El Deek AA, Attia YA, Hannfy MM (2001) Effect of aniseed (Pimpinella anisum), ginger (Zingiber officinale roscoe) and fennel (Foeniculum vulgare) and their mixture on performance of broilers. Arch Geflugelk 67(2): 92-96.

8. Fairley C, Chanter DO, Allister M, Robert NL, Smith H (1985) Effect of avoparcin interaction with anticoccidial compounds on the growth and carcass composition of broilers. Br Poult sci 26(4): 465-471.

9. Guo FC, Kwakkel RP, Soede J, Williams BA, Verstegen MW (2004) Effect of a Chinese herb medicine formulation, as an alternative for antibiotics, on performance of broilers. Br Poult Sci 45(6): 793-797.

10. Sajjad A, Durrani FR (2005) Aniseed extract as immune stimulant and growth promoter in broiler chicks. M.Sc. thesis submitted to NWFP Agricultural University Peshawar. 
11. Kakar AH, Durrani FR (2006) Effect of different levels of ginger infusion on immunity and overall performance of broiler chicks. Thesis submitted to NWFP Agric. Univ. Peshawar (unpublished)

12. Izat AL, Colberg M, Reiber MA, Adams MH, Skinner JT, et al. (1989) Effects of different antibiotics on performance, processing characteristics, and part yield of broiler chickens. Deptt. of Ani. Pout. Sci. Univ. of Arkansas, Fayaetteville, Arkansas 69: 1787-1791.

13. Durrani FR, Ismail M, Amjad M, Suhail SM, Chand N (2004) Effect of different levels of feed added Curcuma longa on overall performance of broiler chicks. J Agri \& Bio Sci 1(2): 9-11.

14. Chand N, Durrani FR, Mian MA, Durrani Z (2005) Effect of different levels of added Berberis lycium on the perfarmance of broiler chicks. Int J Bio Biotech 2(4): 971-974.

15. Niazi MH, Durrani FR (2006) Effect of different levels of Berberis lycium on immunity, lipid profile and growth promoter in broiler chicks. M.Sc. thesis submitted to NWFP Agricultural University.

\section{ISSN: 2574-1241}

DOI: $10.26717 / B J S T R .2020 .30 .004902$

Farman Ullah. Biomed J Sci \& Tech Res

(C) This work is licensed under Creative

Submission Link: https://biomedres.us/submit-manuscript.php
16. Alexander DJ, Chettle NJ (1977) Procedures of heamagglutination and the heamagglutination inhibition tests for avian infectious bronchitis virus. Avian pathology 6(1): 9-17.

17. Jaffari H, Shahid M, Miri SR, Gharebaghi R, Yadegari S (2004) Effects of Trachyspermum copticum L. on Morphine's Withdrawal Syndrome Signs in rats. J Med Plants 3(12): 15-20.

18. Jana U, Bhattacharyya D, Bandopadhyay S, Sur TK, Pandit S, et al. (2005) Antiulcer activity of digitrall: A polyherbal drug in rats. Indian J Pharm 37(6): 406-407.

19. Jandaghi P, kiani S, Hasanzadeh L (2004) Antitussive effect of Carum copticum in guinea pigs. J Ethnopharmacology 97(1): 79-82.

20. Jinag L, Zhang FY, Xu Y, Xinting Z, Yang DP (2005) Effect of gel. Polysaccharide and Acemannan from Aloe vera on brioiler gut flora, microvilli density, immune function and growth performance. Chinese J Vet Sci 25(6): 668-671.

$\begin{array}{ll}\text { BIOMEDICAL } & \text { Assets of Publishing with us } \\ \text { RESEARCHES } & \text { - Global archiving of articles } \\ \text { - Immediate, unrestricted online access } \\ \text { - Rigorous Peer Review Process }\end{array}$

